\title{
The Dietary Treatment of Children with Type I Glycogen Storage Disease with Slow Release Carbohydrate
}

\author{
G. P. A. SMIT, R. BERGER, R. POTASNICK, S. W. MOSES, AND J. FERNANDES \\ Department of Pediatrics, University Hospital, 59 Oostersingel, 9713 EZ Groningen, The Netherlands, and \\ Department of Pediatrics, Soroka Medical Center, Beer-Sheba, Israel [R.P., S.W.M.]
}

\begin{abstract}
Summary
The effect of ingestion of uncooked cornstarch $(2 \mathrm{~g} / \mathrm{kg}$ body weight) in water, uncooked starch $(1 \mathrm{~g} / \mathrm{kg})$ added to a meal, and glucose $(2 \mathrm{~g} / \mathrm{kg})$ in water, was studied in eight patients with type $I^{A}$ glycogen storage disease (GSD) and one patient with type $I^{B}$ GSD. Blood glucose concentrations were determined at 30 -min intervals during each tolerance test; blood lactate, blood insulin, and expiratory hydrogen were determined at 60 -min intervals. The glucose levels remained in the normal range $(\geqslant 1.8 \mathrm{mM})$ during approximately 6.5-9.0 $\mathrm{h}, 3.5-6.5 \mathrm{~h}$, and $2.25-4.0 \mathrm{~h}$ during the three tolerance tests, respectively. The lactate levels differed markedly for the different tests per patient, and for the same type of test between the patients. Blood insulin concentrations after starch administration did not exceed values of $50 \mathrm{mU} / \mathrm{liter}$ above fasting levels and were markedly lower than those after glucose administration (maximum levels of $280 \mathrm{mU} / \mathrm{liter}$ ). The expiratory hydrogen excretion did not increase or only slightly increased after cornstarch administration $(<20 \mathrm{ppm})$.
\end{abstract}

\section{Abbreviations}

GSD, glycogen storage disease

GDF, gastric drip feeding

Patients with deficiency of glucose-6-phosphatase (GSD I ${ }^{\mathrm{A}}$ ) and glucose-6-phosphate translocase $\left(\right.$ GSD $\mathrm{I}^{\mathrm{B}}$ ) cannot produce glucose from glycogen stores or by gluconeogenesis because of their functional absence of glucose-6-phosphatase activity (14). Plasma glucose concentrations therefore completely depend on exogenous sources. The primary aim of treatment is prevention of hypoglycemia. Since the introduction of continuous gastric drip feeding (1), many pediatricians have treated their type I patients with overnight GDF and frequent daytime feeding, resulting in catch-up growth, decrease of hepatomegaly, and improvement of biochemical abnormalities $(7,8,11,12)$. Despite these good results, some major problems remain during longterm treatment. Nocturnal GDF, especially with a glucose amount over $8 \mathrm{mg} / \mathrm{kg} / \mathrm{min}$, renders these patients very carbohydrate-dependent and severe symptoms of hypoglycemia may occur at blood glucose concentrations which have previously been well tolerated (18). Such carbohydrate dependency may occur also at lower glucose quantities administered as $\mathrm{kg} / \mathrm{min}$, though less severely. For some patients and their parents, nocturnal GDF may be too complicated. The positioning of the

Received July 27. 1983; accepted February 7, 1984

Correspondence may be addressed to G. P. A. Smit, Department of Pediatrics, University Hospital, 59 Oostersingel, 9713 EZ Groningen. The Netherlands. gastric tube through the nose may ultimately cause irritation of the mucous membrane, nose bleeding, and nose and ear infections. The present studies were therefore undertaken to explore whether the use of slow release carbohydrate would decrease the carbohydrate dependency of the patient and whether its substitution for GDF would be feasible.

\section{PATIENTS AND METHODS}

Eight patients with biopsy-documented glucose-6-phosphatase deficiency (GSD I ${ }^{A}$ ) and one patient with glucose-6-phosphate translocase deficiency $\left(\right.$ GSD $I^{\mathrm{B}}$ ) were studied. The nine patients, ages 5-13 years, included five male and four female children. All patients were on a low fructose, low galactose diet. Five of the nine patients were on a 12-h nocturnal GDF regimen (carbohydrate intake, $4.5-5.5 \mathrm{mg}$ glucose $/ \mathrm{kg} / \mathrm{min}$ ). All tests, carried out in the metabolic ward, started within $1 \mathrm{~h}$ after the night drip had been discontinued, and in the remaining four patients within 3 $\mathrm{h}$ after the last feeding. The following tolerance tests were performed.

I) Starch test. Uncooked cornstarch, $2 \mathrm{~g} / \mathrm{kg}$ body weight, mixed in 100-150 ml water, was administered through the gastric tube, which was kept in situ in those patients who were on GDF. It was ingested as such by the other patients. The starch-water mixture had to be stirred repeatedly in order to prevent sedimentation of the starch.

2) Starch-meal test. Uncooked cornstarch, $1 \mathrm{~g} / \mathrm{kg}$ body weight, was mixed in curd, the latter amounting to $0.5 \mathrm{~g}$ protein $/ \mathrm{kg}$ body weight. Corn oil, $1 \mathrm{~g} / \mathrm{kg}$ body weight, was added, no other nutrients or flavors being used. The energy content of the meal amounted to $15 \mathrm{kcal} / \mathrm{kg}$ body weight. The "meal" taken with a spoon was usually finished within $10 \mathrm{~min}$.

3) Glucose test. Glucose, $2 \mathrm{~g} / \mathrm{kg}$ body weight in a $20 \%$ solution, was administered orally. After the oral carbohydrate loading, blood glucose concentrations were determined at 30-min intervals; blood lactate, blood insulin levels, and expiratory hydrogen concentration were determined at 60 -min intervals. Blood glucose concentrations were determined immediately by the glucose-oxidase method using a Beckman glucose analyzer. Blood lactate concentrations were determined by the Boehringer method using lactate dehydrogenase. Blood insulin levels were measured according to the double antibody procedure as described by Hales and Randle (13) with slight modifications. The breath samples were collected with a small pediatric size device according to Douwes et al. (6), and $\mathrm{H}_{2}$ concentrations were determined gas chromatographically.

Tests were stopped at the first clinical signs of hypoglycemia or blood glucose concentrations below $1.8 \mathrm{mM}$. Informed consent was obtained from the parents. 


\section{RESULTS}

Table 1 shows the periods of normal blood glucose levels after oral loading with uncooked cornstarch in water (a), uncooked cornstarch in curd (b) and glucose in water (c). Normoglycemia (blood glucose $\geqslant 1.8 \mathrm{mM}$ ) lasted 6.5-9.0, 3.5-6.5, and 2.25-4.25 $\mathrm{h}$, respectively. Prolongation of normoglycemia after cornstarch therefore was 3.0-6.75 h; after cornstarch in curd, it was 0.5$4.25 \mathrm{~h}$, as compared with glucose in water. The increments of blood glucose concentrations during the three tests are presented in Table 2. The glucose increments were lower during the cornstarch tests than during the glucose tests (except in L. S.). This difference applied also to the starch-meal test (except in T. D.).

Lactate concentrations after starch in water varied: in three patients (L. S., T. D., and M. R.), it decreased; in three patients (H. M., R. P., and M. v. D.), no change occurred; and in the other three patients (R. S., E. S., and D. D.), it increased, especially during the last part of the test (Fig. 1). Blood insulin concentrations in all patients were low during the cornstarch tests, and never exceeded values of $50 \mathrm{mU} /$ liter above fasting levels, whereas peak insulin concentrations after oral glucose loading reached maximum levels of $280 \mathrm{mU} /$ liter above fasting levels. Insulin levels during cornstarch in curd tests varied between the former and the latter values. Intestinal symptoms, due to starch indigestion, did not occur. Expiratory hydrogen concentrations were in the normal range (less than $20 \mathrm{ppm}$ ) or only slightly increased.

\section{DISCUSSION}

The use of cooked or partially hydrolized starch in the diets of GSD patients has rendered only moderate results until now (10), as it prolonged postprandial normoglycemia only slightly in comparison to that after glucose. In patients with diabetes mellitus, favorable results have been recently obtained with uncooked starch $(3,4)$. Postprandial blood glucose and insulin peak levels were much lower after its ingestion as compared to glucose. The effects of various starches differed according to their physical state (size of granules, presence of fiber, gelatinizing due to

Table 1. Normoglycemic period in hours after dietary treatment

\begin{tabular}{lccc}
\hline Patient & $\begin{array}{c}\text { Cornstarch } \\
\text { in water }\end{array}$ & $\begin{array}{c}\text { Cornstarch } \\
\text { in curd }\end{array}$ & $\begin{array}{c}\text { Glucose } \\
\text { in water }\end{array}$ \\
\hline L. S. & 6.5 & & 3.5 \\
H. M. & 8.0 & 3.5 & 4.25 \\
R. S. & 8.5 & 4.5 & 2.5 \\
T. D. & 7.0 & 4.0 & 3.5 \\
E. S. & 8.5 & 6.0 & 2.5 \\
R. P. & 8.0 & 6.5 & 4.0 \\
D. D. & 7.0 & 5.0 & 3.5 \\
M. v. D. & 9.0 & 6.5 & 2.25 \\
M. R. & 6.5 & 4.5 & 3.0 \\
\hline
\end{tabular}

Table 2. $\Delta$ Blood glucose after dietary treatment*

\begin{tabular}{lccc}
\hline Patient & $\begin{array}{c}\text { Cornstarch } \\
\text { in water }\end{array}$ & $\begin{array}{c}\text { Cornstarch } \\
\text { in curd }\end{array}$ & $\begin{array}{c}\text { Glucose } \\
\text { in water }\end{array}$ \\
\hline L. S. & 4.8 & & 4.5 \\
H. M. & 0.3 & 1.9 & 9.6 \\
R. S. & 3.2 & 1.9 & 8.6 \\
T. D. & 3.2 & 8.1 & 7.1 \\
E. S. & 1.7 & 0.6 & 6.8 \\
R. P. & 1.2 & 4.2 & 5.5 \\
D. D. & 3.7 & 3.8 & 5.8 \\
M. v. D. & 1.0 & 1.2 & 5.9 \\
M. R. & 1.1 & 4.7 & 3.2 \\
\hline
\end{tabular}

* $\Delta$ blood glucose, difference between initial and peak blood glucose concentration $(\mathrm{mM})$.

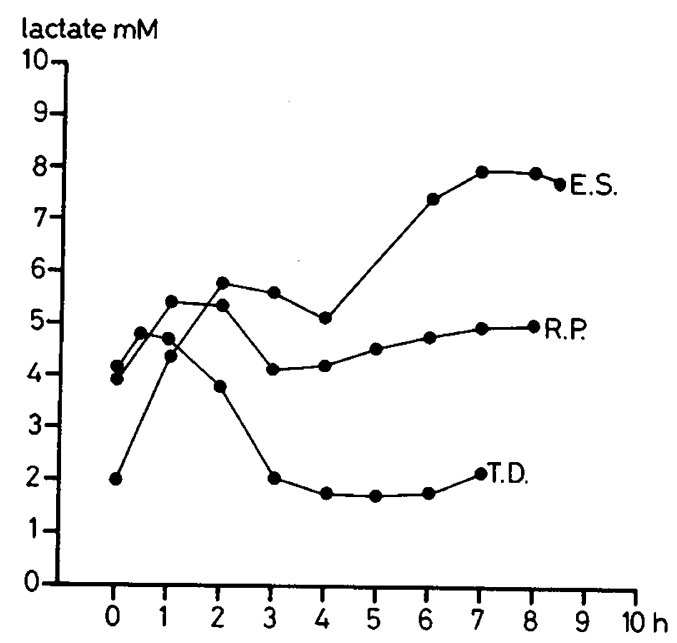

Fig. 1. Different responses of blood lactate concentrations after uncooked cornstarch $(2 \mathrm{~g} / \mathrm{kg})$ in water in three patients.

cooking) $(5,15-17)$. The best results were obtained with uncooked starches and of these cornstarch had the most pronounced effect.

In keeping with these observations, Sidbury tried uncooked cornstarch in water in GSD I patients who wanted to discontinue their GDF (personal communication). In the present study, we confirmed and enlarged the results of Chen et al. (2), by comparing the effects of uncooked cornstarch in water, uncooked cornstarch added to a meal, and glucose in water on glucose and lactate blood levels. After starch in water, all nine patients showed a marked prolongation of normoglycemia without the precipitous changes observed after the administration of glucose in water. The effects of uncooked cornstarch added to curd were intermediate between those after cornstarch in water and after glucose in water (Tables 1 and 2). Contrary to the similarity of the glucose curves after starch in water, the lactate curves showed marked variation among patients. For these differences, we have no explanation yet. A moderate hyperlactacidemia should be maintained as lactate appears to be a fuel for the brain as is glucose (9). The only means to achieve this would be to "titrate" the amount and type of starch added to the meals against blood lactate and glucose levels. The optimal dose of starch to be added to the meals varies between 1 and $2 \mathrm{~g} / \mathrm{kg}$ body weight twice a day. The first dose should be administered either through the gastric tube just before its withdrawal after the night in patients with GDF, or added to curd or yoghurt at breakfast in patients without GDF. The composition of the latter mixture may serve for the second starch dose at luncheon, too. Simultaneous addition of mono- and disaccharides interferes with the steady state of blood glucose induced by starch due to the insulinogenic effect of the former carbohydrates (results not shown). These rapidly absorbed carbohydrates should therefore be limited or avoided. The two starch servings would not only make the patient less dependent on a strict timetable for his meals, but would also decrease the number of meals at daytime to the normal three to four.

There is no reason for apprehension on long-term effects of starch administration on somatic development of and biochemical abnormalities in the patient, but we prefer to postpone the substitution of starch for GDF till the puberal growth spurt of the child has been completed.

\section{REFERENCES}

1. Burr IN, O'Neall JA, Karson DB, Howard LJ, Green HL 1974 Comparison of the effect of total enteral nutrition, continuous intragastric feeding and portocaval shunt on a patient with type I glycogen storage disease. J Pediatr 85:792

2. Chen YT, Cornblath M, Sidbury JB 1983 Cornstarch therapy in type I glycogen storage disease (GSD). Pediatr Res 17:208A

3. Collier G, O'Dea K 1982 Effect of physical form of carbohydrate on the 
postprandial glucose, insulin and gastric inhibitory polypeptide responses in type 2 diabetes. Am J Clin Nutr 36:10

4. Crapo EA, Insel J, Sterling M, Koperman OG 1981 Comparison of serum glucose, insulin and glucagon responses to different types of complex carbohydrates in non-insulin-dependent diabetic patients. Am J Clin Nutr 34:184

5. De Vizia B, Ciccimarra F, De Cicco N, Auricchio S 1975 Digestibility of starches in infants and children. J Pediatr 86:50

6. Douwes AC. Fernandes J, Rietveld W 1978 Hydrogen breath test in infants and children: sampling and storing expired air. Clin Chim Acta 82:293

7. Ehrlich RM, Robinson DH, Freedman MH, Howard MJ 1978 Nocturnal intragastric infusion of glucose in management of defective gluconeogenesis with hypoglycemia. Am J Dis Child 132:241

8. Fernandes J, Jansen H, Jansen DC 1979 Nocturnal gastric drip feeding in glucose-6-phosphatase deficient children. Pediatr Res 13:25

9. Fernandes J, Berger R, Smit GPA 1984 Lactate as a cerebral metabolic fuel for glucose-6-phosphatase deficient children. Pediatr Res 18:335

10. Fernandes J 1975 Hepatic glycogen storage disease. In: Raine DN (ed) The Treatment of Metabolic Disease. MTP Co. Ltd., Lancaster, pp 115-149

11. Greene HL, Slonim AE, Burr IN, Moran JR 1980 Type I glycogen storage disease: five years of management with nocturnal intragastric feeding. J Pediatr
$96: 590$

12. Greene HL, Slonim AE, Burr IN 1979 Type I glycogen storage disease: a metabolic basis for advances in treatment. Adv Pediatr 26:63

13. Hales CN, Randle PJ 1963 Immunoassay of insulin with insulin-antibody precipitate. Biochem J 88:137

14. Howell RR 1983 The glycogen storage diseases. In: Stanbury JB, Wyngaarden JB, Fredrickson DS (eds) The Metabolic Basis of Inherited Disease. McGrawHill, New York, pp 149-152

15. O'Dea J Snow P. Nestel P 1981 Rate of starch hydrolysis in vitro as a predicto of metabolic responses in complex carbohydrate in vivo. Am $\mathrm{J}$ Clin Nutr 34:1991

16. Reaven GM 1980 Effect of differences in amount and kind of dietary carbohydrate on plasma glucose and insulin responses in man. Am J Clin Nutr 32:2568

17. Snow P, O'Dea K 1981 Factors affecting the rate of hydrolysis of starch in food. Am J Clin Nutr 34:2721

18. Stanley CA, Mills JL. Baker L 1981 Intragastric feeding in type I glycogen storage disease: factors affecting the control of lactic acidemia. Pediatr Res 15:1504

\title{
The Activity of Hepatic Lipase and Lipoprotein Lipase in Glycogen Storage Disease: Evidence for a Circulating Inhibitor of Postheparin Lipolytic Activity
}

\author{
D. P. R. MULLER AND T. R. GAMLEN \\ Department of Child Health, Institute of Child Health, London WCIN IEH, England
}

Summary

This study was designed to investigate the greatly reduced activities of hepatic lipase and lipoprotein lipase in postheparin plasma of patients with glycogen storage disease (GSD). Evidence for the presence of a circulating inhibitor in the plasma of GSD patients prior to the establishment of metabolic control was provided by the following observations.

The hepatic lipase activity from patients with GSD gave a nonlinear relationship with time, maximum activity being obtained after $5 \mathrm{~min}$ whereas normal postheparin plasma showed a linear relationship for at least $20 \mathrm{~min}$. The addition of GSD plasma to a normal postheparin plasma resulted in inhibition of the normal postheparin lipolytic activity. The inhibition showed a dose response, with 10 and $30 \mu l$ of the GSD plasma giving 22 and $65 \%$ inhibition after $20 \mathrm{~min}$, respectively. Serial dilution of GSD postheparin plasma gave increasing activity of hepatic lipase when expressed per ml of plasma. Thus, a 1:100 dilution gave a normal activity of $15 \mu \mathrm{mol} / \mathrm{ml} / \mathrm{h}$ whereas a $1: 10$ dilution gave less than $10 \%$ of this activity. After affinity chromatography of the GSD postheparin plasma on heparin/Sepharose, the inhibition was removed and a normal lipolytic activity was obtained.

Received January 5. 1984.

Correspondence should be sent to D. P. R. Muller, Department of Child Health, Institute of Child Health, 30 Guilford Street, London WCIN I EH, England.

T. R. G. thanks the National Fund for Research into Crippling Diseases for financial support.
Abbreviations

GSD, glycogen storage disease

FH, familial hypercholesterolemia

HLip, type I hyperlipoproteinemia

Type I glycogen storage disease (glucose-6-phosphatase deficiency) is characterized by hepatomegaly, growth retardation, fasting hypoglycemia, metabolic acidosis, and hyperlipidemia. The hyperlipidemia which is predominantly a hypertriglyceridemia appears to result from both an increase in synthesis (16) and a decrease in clearance (9) of circulating triglyceride.

Triglycerides are transported in the circulation by triglyceriderich lipoproteins (chylomicrons and very low density lipoprotein). They are cleared from the circulation by the action of lipoprotein lipase which is located on the capillary endothelium of extrahepatic tissues but can be released into the circulation by low doses of intravenous heparin. Postheparin plasma, however, also contains a lipase of hepatic origin which has properties different from lipoprotein lipase. We $(12,13)$ and others $(8)$ have reported that activities of both the lipoprotein lipase and hepatic lipase are reduced in postheparin plasma from patients with type I GSD. Treatment of this disorder by frequent feeds or nocturnal gastric drip results in marked improvement of the hyperlipidemia (15) and an increase in the activity of lipoprotein and hepatic lipase has been reported (8). These changes suggested to us that treatment might have resulted in the removal of a circulating 